\title{
Chapter 7 \\ Potential of the Task-Based Learning for the Sustainable Development of Food Technology
}

\author{
Manuela Niethammer
}

\subsection{Introduction}

The sustainable development of food technology in countries of Central Asia requires that those professionals at various skill levels are trained, who are not limited to coping only with the tasks that entail innovative technologies. Instead, it requires professionals who shape and develop these innovations further. Potentials of skilled worker expertise for sustainable workplace organisation have been in discussion since the 1980s of the twentieth century (cp. Rauner 1988).

This expectation from skilled workers results in demands related to vocational education and training. The skilled workers must be empowered not only to understand the world of work and to "operate" the technical systems but also to question and optimise these continuously. This must be reflected in the didactic set-up of the vocational teaching-learning processes. Learning opportunities must be initiated in which the trainees are introduced to the organisation and sustainable development of their respective work domain. The underlying problem-solving processes must be addressed and reflected for learners. The laboratory training and the comparative work trial in particular offer a good opportunity for this.

The following section classifies the comparative work trial as a method in vocational education. The statements are based on the approach of skills-based and action-oriented vocational training, which was established with the reorganisation of occupations in Germany since the 1990s. With the so-called learning field concept, professional work, or more specifically occupational tasks, was made the fundamental reference point for vocational learning (see Bader 2003).

M. Niethammer $(\square)$

Faculty of Education, Technische Universität Dresden, Dresden, Germany

e-mail: manuela.niethammer@tu-dresden.de 


\subsection{Occupational Tasks as Reference for Vocational Learning or Which Content Is Important for Professional Work and thus for Learning?}

Vocational tasks present an important reference point for skills-based vocational training. This also applies to the analysis of the relevant content (technical analysis), the methodological structuring of the teaching-learning settings as well as for the planning of performance or skills assessment.

For the analysis of education-related contents of the work, it must be considered that the concrete implementation of professional work is limited by overriding factors such as the organisation of work, the company size and structure, etc. In hierarchical working structures, the skilled workers are accustomed to routine tasks, whereas in companies with participatory organisational structures, skilled workers are more involved in addressing problematic and development tasks. The knowledge required for the work tasks, which can be further divided into practical and technical knowledge (Franke 2001; see also modelling approaches, such as theory of action regulation, Hacker and Ulich 1986), also correlates with these factors.

Practical knowledge here includes knowledge of adequate thinking and working actions and technical operations to perform a work task in view of the objective (Franke 2001, p. 17). If one compares such an action with a defined change of a work item, the action is defined as process unit. The practical knowledge includes the logical layout of all the process units necessary for the order processing.

The process unit is the smallest reference quantity for allocating the expertise which comprises of any relevant facts, circumstances and relations that characterise and consequently justify the course of action or order processing. These include at least the following aspects with regard to a process unit ${ }^{1}$ :

- Work items (e.g. structure and properties of raw materials and products)

- Mechanisms and effects of natural and technological processes that lead to desirable (e.g. kneading of dough, fermenting tea) or undesirable (formation of grinding areas in the dough) changes in the work items, including the process conditions (e.g. temperature, dwell times, energy input)

- The functioning and operation of the equipment (hand-held vs. large-scale equipment), including the necessary auxiliary media, energy, etc.

For the structuring of educational content in the context of work tasks, the approach sketched in Fig. 7.1 is discussed in the didactics of professional disciplines (cp. Niethammer 2006; Kuntzen et al. 2010; Becker et al. 2010).

The general contents and content relationships outlined in Fig. 7.1 (every double arrow represents potential relationships between the concepts) should be underpinned

\footnotetext{
${ }^{1}$ Regardless of this work-based system, the technical expertise relevant in the context of the specific work task may be a subject of various scientific disciplines (food chemistry, food technology, biochemistry, chemical engineering, history, economics, etc.) and be present in a different systematically structured way depending on the subject area.
} 


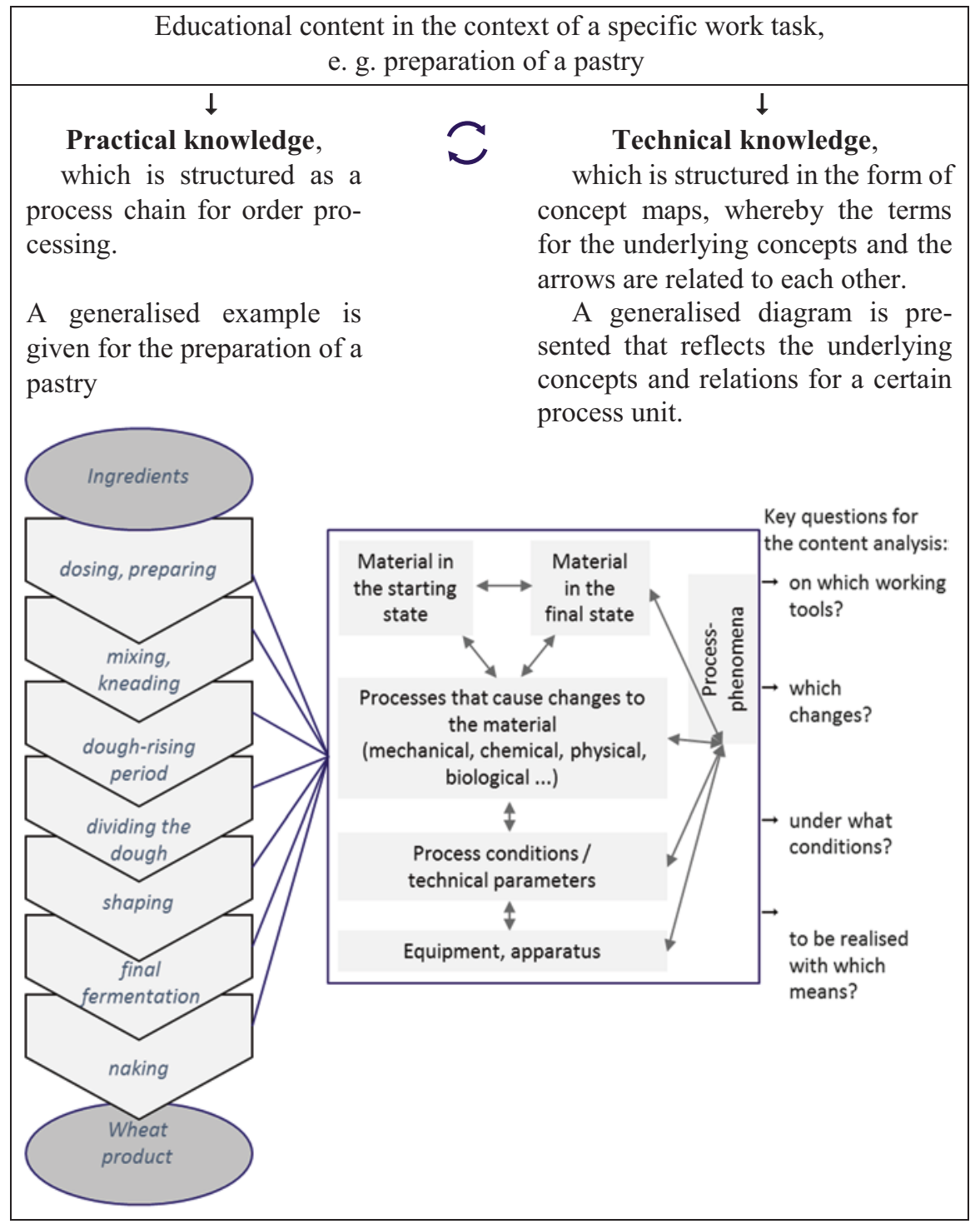

Fig. 7.1 Approach to structuring of educational contents in the context of professional work tasks as practical and technical expertise 


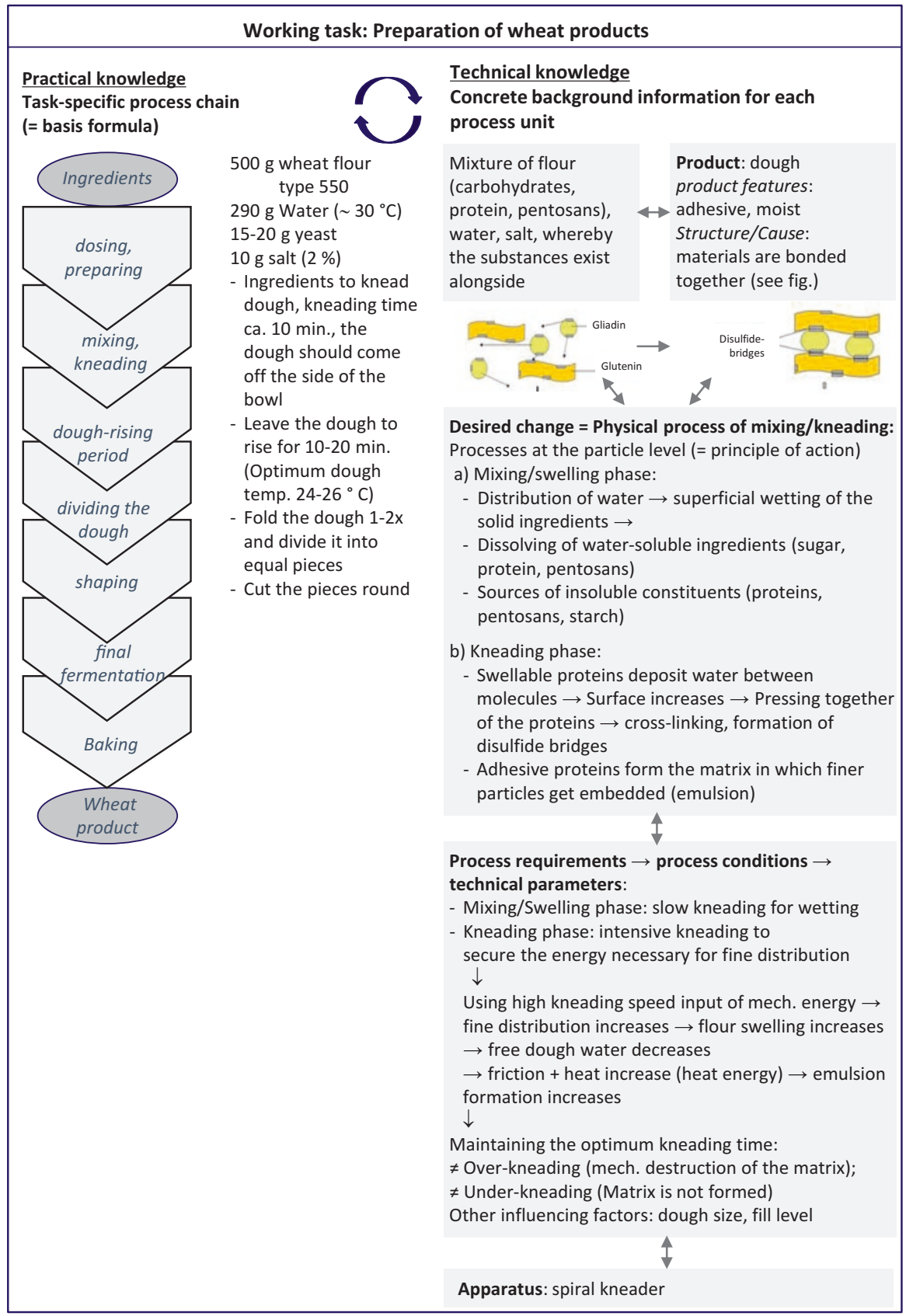

Fig. 7.2 Exemplary substantiation of task-specific practical and technical expertise using the example of the work task "preparation of wheat products" 
specifically for each work item. In Fig. 7.2, this is illustrated for the task "preparation of wheat bread".

The technical and practical knowledge is not necessarily important for the realisation of every work task. This depends on the type of work item. In other words, the work requirements or task types can be classified through the relevance of the practical or technical knowledge to deal with a specific work task or situation.

Tasks that can be managed based solely on action-related knowledge have certain minimum requirements. Action-related knowledge corresponds to a minimum knowledge structure (cp. Frank et al. 2016). The requirements increase with the extent of the necessary specialised knowledge. If practical and specialised knowledge is necessary for solving a task, which can be correlated, this corresponds to the optimal knowledge structure (cp. Frank et al. 2016). Regardless of this differentiation, the respective required technical and/or practical knowledge has different characteristics that determine the difficulty level depending, inter alia, on the complexity or the necessary abstraction level of knowledge (see Niethammer 2006, Becker 2010; Kuntzen et al. 2010; Becker et al. 2010).

In correlation with this understanding of the knowledge required for the work task management, the work tasks can be classified as:

- Routine tasks as those that are to be dealt with following strict rules such that in this case, the practical knowledge provides a sufficient basis for correctly addressing the task.

- Problematic objects as tasks in which an incompletely defined situation or external influences mean that a routine execution is not possible. In this case, the condition-related appropriate course of action has to be generated first. For example, the raw materials in Central Asia exhibit significant quality differences, which are encountered through variety selection and genetic modification in industrialised countries. The basis for solving problematic tasks is both practical as well as technical knowledge.

- Optimisation or development tasks that are to be dealt with in a team. For these tasks, the routine processes should be questioned and modified (cp. e.g. Eberhardt and Schlegel 2011). In addition to the task-related practical and technical knowledge, they also require knowledge of the proper planning of development processes. If sustainable products are created and corresponding manufacturing processes are generated or planned in a resource-efficient manner, substantive and methodological expertise is required. Products or processes can only be optimised if the influence of each parameter on the process or the product is known or studied systematically. The latter includes, for example, that in every empirical analysis, only one parameter is varied keeping all other variables constant. Such knowledge is beyond the scope of the classical skilled workers. However, it is important if they are to contribute their expertise for sustainable workplace shaping. 
The methodological planning of teaching-learning processes must satisfy the particular objectives and contents of vocational training. Thus, the development of occupational competence is ${ }^{2}$ linked to the fact that the learners are already faced with tasks in training for which responsibility will be handed over to them later during their professional work life. A person can only learn to manage work tasks by practice. This implies that the pending work item is analysed, the expected results are derived, facts are already known, open questions are differentiated and alternative solutions are drawn up, implemented and controlled (principle of complete action). At that moment, the work task becomes a learning task for the trainee.

If work tasks are used as reference points of learning in vocational education, then each task carries a different learning potential, resulting from the abovementioned requirements. They reveal themselves in the issues that arise most likely during the implementation of the task.

If a food item is being prepared following a recipe, questions will arise regarding the necessary steps and their execution (practical knowledge). If the ingredients are known as such and the instructions are clear, questions regarding the properties and the chemical characteristics of the ingredients or the mechanisms of the required technological or natural processes (mixing, kneading, baking, cooking, etc.) are hardly of any relevance.

Another situation and thus a different learning potential arises when the desired and expected effects of a certain process are not seen, e.g. the dough does not have the right consistency or the cake seems to have cuts after baking. The search for possible execution errors makes one scrutinise the entire process in depth. This implies issues, based on the used ingredients, the parameters and the possible interfering factors on the process (factual and procedural knowledge).

The sustainable development or optimisation of recipes also implies that the ingredients, the process parameters and possibly also the technology are questioned in order to generate a more sustainable recipe. This can include the substitution of ingredients with healthier ones as well as an increase in the resource-efficient products by minimising time or energy. Questions that may be associated herewith such as:

- Which substances are they? Which properties are technologically or nutritionally significant? Can these be influenced? What causes them? (The response may require the consideration of the chemical structure of the substances.)

- Which material changes occur? Why?

- What processes take place in the technological processing of the materials? (Model conceptions of the processes taking place at the micro level facilitate the derivation of process parameters and the justification of the process phenomena.)

\footnotetext{
${ }^{2}$ (Professional) competence is understood as the willingness and ability of an individual to recognise, develop and implement objective action potentials and subjective development potentials in professional, social and personal situations.
} 
- Which conditions are conducive and which ones inhibit the process? Why?

- Which devices/equipment are suitable to ensure the necessary conditions/parameters? Which occupational safety measures result from this?

These questions are based heavily on the technical expertise and the knowledge of action. Development and optimisation tasks also comprise of the learning potential outlined for routine and problematic tasks. In addition, it also needs to be clarified that which criteria are important for the implementation of a development or optimisation process.

- Which influencing factors should be examined in what way?

- Which variables are to be held constant in order to be able to assign the effect clearly?

- How should the complex exploration process be logged such that uninvolved parties can also use the data?

It is clear that the task types provide different learning opportunities that are equally reflected in the teaching goals and content.

\subsection{Didactic Concepts of Work-Based Learning and Their Potential for Sustainable Workplace Organisation}

Depending on the goal-content relations, there are also some different didactic concepts for the presentation of the task of dealing with the work, including the resulting questions. Due to the complexity of the learning processes, the methodological design of teaching and learning processes should also be discussed with a multiperspective approach in order to reflect all the relevant aspects. That cannot be done at this point. The focus should rather be given to the appropriate action patterns.

In the following tabular assignment, the work tasks are classified based on their learning potential, and the appropriate action patterns for didactic design of the respective task-based learning processes are assigned (cp. Table 7.1).

The comparative work trial corresponds to the systematic testing of work regulations under different conditions (independent variable), through which their effect on the entire work process (dependent variables) can be studied and characterised. To clearly understand the relationship between the respective different conditions and the achieved effects, the other conditions must be kept constant.

These "conditions" in the work process may relate to all elements of the work system. The following may be varied:

- Substances may be varied in type and quantity (material aspects).

- Technologies and working techniques, such as stirring vs. kneading (processrelated aspects). 
Table 7.1 Classification of work tasks

\begin{tabular}{l|l|l|l}
\hline Work tasks & Examples & $\begin{array}{l}\text { (Special) learning } \\
\text { potential }\end{array}$ & $\begin{array}{l}\text { Suitable educational concepts } \\
\text { (action patterns) }\end{array}$ \\
\hline Routine tasks & $\begin{array}{l}\text { Producing a food } \\
\text { product according } \\
\text { to a given recipe }\end{array}$ & Practical knowledge & $\begin{array}{l}\text { Four-step method } \\
\text { (preparation, demonstrating, } \\
\text { imitating, practising), learning } \\
\text { guidelines method }\end{array}$ \\
\hline $\begin{array}{l}\text { Problematic } \\
\text { tasks }\end{array}$ & $\begin{array}{l}\text { Recognising and } \\
\text { rectifying an } \\
\text { execution error, } \\
\text { varying recipes } \\
\text { depending on the } \\
\text { conditions }\end{array}$ & $\begin{array}{l}\text { Technical and practical } \\
\text { knowledge }\end{array}$ & $\begin{array}{l}\text { Case method, project learning, } \\
\text { role-playing, simulation game } \\
\text { subordinated: research, } \\
\text { teacher-student conversation, } \\
\text { lecture, experiments, incl. } \\
\text { various cognitive processes }\end{array}$ \\
\hline $\begin{array}{l}\text { Development } \\
\text { or optimisation } \\
\text { task }\end{array}$ & $\begin{array}{l}\text { Developing new } \\
\text { products, optimising } \\
\text { recipes, etc. }\end{array}$ & $\begin{array}{l}\text { Technical and practical } \\
\text { expertise and knowledge } \\
\text { regarding the } \\
\text { methodology of } \\
\text { systematic development } \\
\text { of products/technologies }\end{array}$ & $\begin{array}{l}\text { As stated above, as well as } \\
\text { comparative work trial }\end{array}$ \\
\hline
\end{tabular}

${ }^{a} \mathrm{~A}$ comprehensive picture of the diversity of different paths to knowledge cannot be sketched at this point

- Process parameters, e.g. temperature, dwell time, pressure, and speed (processrelated aspects).

- Apparatus such as beater vs. mixer (apparatus-related aspects).

The comparative work trial may be considered a scientific method on which the optimisation and development of new sustainable products or processes is based. Unlike the simple experimental exploration of the effects of a parameter on a work process, the consistency of all other parameters is explicitly controlled. When exploring, the observation is solely directed towards the expected effect, and other consequences are hardly controlled. The analysis may be so highly focused that the relevant conditions are entirely neglected in the overall consideration. Likewise, the comparative work trial is to be distinguished from "test baking", with which the quality of the flour from the new delivery or grain harvest was also determined in the Middle Ages. However, the various test parameters were randomly set and varied here (see Horlacher 2015).

The requirements to be met by the learners in the comparative work trial are enormous. In order to understand and interpret the effects in comparative work trial correctly, a systematic documentation of all relevant process-related and productrelated data is necessary. These shall be clearly documented for several manufacturing processes, where only one parameter is varied. In addition, the expected/desired values (target values or comparative values of the standard variant) shall be compared with the achieved parameters (actual values). By linking the different per- 
spectives, the data situation becomes complex. Documentation and interpretation of the data requires a high degree of structuredness and cognitive ability. For illustrating this, a possible documentation for a comparative work trial for baking bread is given in the Annex.

The development of skills for sustainable development presents a particular challenge for the teachers as well. The comparative work trial offers a didactic concept to address and reflect the complex relations as well as methodological aspects that underlie the respective development or optimisation task with the learners.

\section{References}

Bader, R. (2003). Lernfelder konstruieren - Lernsituationen entwickeln: Eine Handreichung zur Erarbeitung didaktischer Jahresplanungen für die Berufsschule. Die berufsbildende Schule, 55, 210-217.

Becker, M. (2010). Wie lässt sich das in Domänen verborgene "Facharbeiterwissen" erschließen? In M. Becker, M. Fischer, \& G. Spöttl (Eds.), Berufliche Bildung in Forschung, Schule und Arbeitswelt: Bd. 5. Von der Arbeitsanalyse zur Diagnose beruflicher Kompetenzen. Methoden und methodologische Beiträge aus der Berufsbildungsforschung (pp. 54-66). Frankfurt am Main: Lang.

Becker, M., Fischer, M., \& Spöttl, G. (Eds.). (2010). Berufliche Bildung in Forschung, Schule und Arbeitswelt: Bd. 5. Von der Arbeitsanalyse zur Diagnose beruflicher Kompetenzen: Methoden und methodologische Beiträge aus der Berufsbildungsforschung. Frankfurt am Main: Lang.

Eberhardt, C., \& Schlegel, B. (2011). Fördert ECVET den Aufbau eines europäischen Mobilitätsverbundes?: Das Beispiel CREDCHEM. In C. Eberhardt (Ed.), Wissenschaftliche Diskussionspapiere (BIBB): Vol. 132. Mit ECVET zu besserer Mobilität? Von der europäischen Empfehlung zur Erprobung in der Praxis. Ergebnisse aus den ECVET-Pilotprojekten SME Master Plus, AEROVET, CREDCHEM und VaLOGReg (2009-2012) (pp. 30-41). Bonn: Bundesinsitut für Berufsbildung (BIBB).

Frank, C., Bernholt, S., \& Parchmann, I. (2016). Modellierung des Zusammenhangs allgemeiner und beruflicher Kompetenzen für die Domäne Chemie. Zeitschrift für Didaktik der Naturwissenschaften, 22(1), 43-60. https://doi.org/10.1007/s40573-015-0040-x.

Franke, G. (2001). Komplexität und Kompetenz: Ausgewählte Fragen der Kompetenzforschung (1., unveränd. Nachdr). Berichte zur beruflichen Bildung. Bielefeld: Bertelsmann.

Hacker, W., \& Ulich, E. (1986). Arbeitspsychologie: Psychische Regulation von Arbeitstätigkeiten; Neufassung von "Allgemeine Arbeits- und Ingenieurpsychologie" (Neufassung, 1. Aufl.). Schriften zur Arbeitspsychologie: Vol. 41. Bern: Huber.

Horlacher, F. (2015). Unpublished lecture notes.

Kuntzen, S., Howe, F., \& Hägele, T. (2010). Arbeitsprozessorientierung in der Beruflichen Bildung: Analyse und Beschreibung von Arbeitsprozessen mit Hilfe der Arbeitsprozessmatrix. In M. Becker, M. Fischer, \& G. Spöttl (Eds.), Berufliche Bildung in Forschung, Schule und Arbeitswelt: Bd. 5. Von der Arbeitsanalyse zur Diagnose beruflicher Kompetenzen. Methoden und methodologische Beiträge aus der Berufsbildungsforschung (pp. 90-110). Frankfurt am Main: Lang. 
Niethammer, M. (2006). Berufliches Lernen und Lehren in Korrelation zur chemiebezogenen Facharbeit: Ansprüche und Gestaltungsansätze. Zugl.: Dresden, Techn. Univ., Habil.-Schrift, 2005. Berufsbildung, Arbeit und Innovation Dissertationen, Habilitationen: Vol. 7. Bielefeld: Bertelsmann.

Rauner, F. (1988). "Gestalten" - eine neue gesellschaftliche Praxis. Reihe: Vol. 21. Bonn: Verl. Neue Gesellschaft.

Open Access This chapter is licensed under the terms of the Creative Commons Attribution 4.0 International License (http://creativecommons.org/licenses/by/4.0/), which permits use, sharing, adaptation, distribution and reproduction in any medium or format, as long as you give appropriate credit to the original author(s) and the source, provide a link to the Creative Commons license and indicate if changes were made.

The images or other third party material in this chapter are included in the chapter's Creative Commons license, unless indicated otherwise in a credit line to the material. If material is not included in the book's Creative Commons license and your intended use is not permitted by statutory regulation or exceeds the permitted use, you will need to obtain permission directly from the copyright holder. 